\title{
Fórmulas y estructuras descriptivas en el Romancero Viejo
}

\section{Formulas and descriptive structures in the Romancero Viejo}

\author{
Aurelio GonzÁlez \\ El Colegio de México
}

El romance es una balada, y por tanto pertenece a un género épico-lírico esencialmente narrativo, por lo cual la descripción es un recurso secundario en la construcción textual, pero no por ello sin importancia y con diversas funciones en la organización del relato. Algunas de sus funciones son recalcar la expresividad de una circunstancia o un personaje determinado apoyando los elementos narrativos. En la descripción se utilizan abundantemente los elementos formulísticos que caracterizan el lenguaje tradicional del Romancero, que es un lenguaje condensado y económico que no se extiende en descripciones.

La descripción es un recurso empleado como una síntesis; puede apoyarse en el recurso de la enumeración; puede ser contrastiva, esto es, la que va contraponiendo elementos opuestos para subrayar el sentido de una situación o la condición de un personaje, y también puede llenar la función de proporcionar indirectamente la caracterización del personaje y los antecedentes de la historia.

Palabras clave: Romancero, tradicionalidad, descripción, formulismo, enumeración, función narrativa

The romance is a ballad, an epic-lyric literary form and essentially narrative. In this genre the description is secondary in the textual construction, but have importance and several functions in the organization of the text. Some of these functions are remark the expressivity of a personage or a circumstance, supporting specific narrative elements. In the descriptions are used the formulistic elements characteristic of the traditional language of Romancero, a condensed and economic language that is very limited in descriptions.

The description is a resource used as a synthesis, may be supported by the enumeration, that may be contrastive and oppose elements to underline the sense of a situation or the condition of a personage. Also the description can give, indirectly, the characterization of the personage and the antecedents of the story.

KeYwords: Spanish ballad, traditional text, description, formulistic expression, enumeration, narrative function

O i partimos de la consideración que el romance es una balada, y por tanto se trata de un texto que pertenece a un género épico-lírico esencial$\checkmark$ mente narrativo, y que esta característica es definitoria del género, la 
descripción será entonces un recurso secundario en la construcción textual, pero no por ello sin importancia y con diversas funciones en la organización del relato. En este uso minoritario de la descripción también hay que tomar en cuenta que el estilo tradicional en textos narrativos, tanto viejos como modernos, se caracteriza por el uso de un lenguaje condensado y económico que no se diluye o extiende en descripciones, esto es: un lenguaje que privilegia la sucesión de las acciones y las expresa con una economía discursiva acorde con las necesidades de la transmisión oral que implica facilitar la conservación textual en la memoria del transmisor, con independencia de que el texto medieval posteriormente haya sido adaptado a otros medios de difusión como pueden ser los cancioneros musicales o los pliegos sueltos impresos a partir del siglo XvI, a través de las cuales han llegado a nosotros muchos romances viejos medievales.

Por el contrario, la descripción es elemento constructivo fundamental en buen número de canciones líricas de origen medieval. Muchas pueden ser canciones dedicadas a sentimientos, situaciones particulares, incluso lugares o ciudades y a personajes y en ellos la descripción es dominante. Esto hace que la proximidad de ambos géneros genere influencias e interacciones mutuas, basta pensar, por ejemplo, en la existencia de romances líricos.

Aceptando que la descripción es un recurso minoritario en el Romancero, sin embargo, cuando se emplea no es meramente un ornato lírico, sino que también puede llenar diversas funciones narrativas. Así, lo primero que encontramos al revisar versiones de romances viejos es que la descripción es un recurso empleado como una síntesis, útil para subrayar el sentido global, los valores de un personaje determinado o su condición. Desde luego la descripción enumerativa se hace a partir de elementos que reconoce fácilmente la comunidad. La descripción puede ser mínima, enumerando, por ejemplo, en forma tríadica los elementos caracterizadores del héroe guerrero.

$$
\begin{aligned}
& \text { Por las riberas de Arlança Bernardo el Carpio cavalga } \\
& \text { con un cavallo morcillo enjahezado de grana, } \\
& \text { gruessa lança en la su mano, armado de todas armas. } \\
& \text { Toda la gente de Burgos le mira como espantada, } \\
& \text { porque no se suele armar sino a cosa señadada. }
\end{aligned}
$$

(Por las riberas de Arlanza, Juan Timoneda,

$$
\text { Rosas de romances, } \mathrm{f} . \mathrm{x} \text { ) }
$$

En este caso, Bernardo del Carpio se caracteriza simplemente al describirlo montado en su caballo, lujosamente adornado, y armado con una lanza 
poderosa, todos elementos propios del caballero y podríamos decir que tópicos.

Pero la descripción también puede ser muy amplia y detallada. Por ejemplo, la siguiente versión que destaca por la acumulación de elementos descriptivos que corresponden a la imagen estereotipada del rey Rodrigo como perdedor, en realidad esta descripción es la construcción y caracterización del personaje:

$$
\begin{aligned}
& \text { Rodrigo dexa sus tierrass y de el real se salía: } \\
& \text { solo va el desventurado, que no lleva compañía; } \\
& \text { el cavallo de cansado ya mudar no se podía: } \\
& \text { camina por donde quiere, que no le estorva la vía. } \\
& \text { El rey va tan desmayado que sentido no tenía: } \\
& \text { muerto va de sed y hambre que de velle era manzilla; } \\
& \text { iva tan tinto de sangre, que una brasa parecía. } \\
& \text { Las armas lleva abolladas, que eran de gran pedrería; } \\
& \text { la espada lleva hecha sierra de los golpes que tenía; } \\
& \text { el almete de abollado en la cabeça se le hundía; } \\
& \text { la cara lleva hinchada del trabajo que sufría. } \\
& \text { (Romance del rey don Rodrigo como perdió a España, } \\
& \text { Cancionero de romances s. a., ff. 126-127) }
\end{aligned}
$$

La descripción se apoya en el recurso de la enumeración en la que cada elemento mencionado tiene una ampliación, ya sea causal o explicativa del sentido o efecto que tiene. La imagen es claramente la de un guerrero derrotado, pues el daño que se describe, además del estado agotado del monarca y su caballo, es de las armas y armadura. A esta descripción del derrotado monarca godo sigue otra, a través de los ojos del propio rey, y ahora lo que se describe es el campo de batalla y sus huestes derrotadas:

\footnotetext{
Subióse encima de un cerro el más alto que veía: dende allí mira su gente cómo iva de vencida. 
Probablemente en esta riqueza visual de las descripciones radique parte de la popularidad de este romance que recogieron desde los pliegos sueltos hasta las colecciones más importantes de romances.

La descripción contrastiva, esto es, la que va contraponiendo elementos opuestos para subrayar el sentido de una situación o la condición de un personaje, también es un recurso muy útil para la creación del estereotipo del héroe popular del vasallo rebelde, distinto de la imagen del Cid como el vasallo leal del cantar épico:

Cavalga Diego Laynez al buen rey besar la mano; consigo se los llevava los trezientos hijos dalgo. Entr'ellos yva Rodrigo el sobervio castellano; todos cavalgan a mula, sólo Rodrigo a cavallo; todos visten oro y seda, Rodrigo va bien armado; todos espadas ceñidas, Rodrigo estoque dorado; todos con sendas varicas, Rodrigo lança en la mano; todos guantes olorosos, Rodrigo guante mallado; todos sombreros muy ricos, Rodrigo casco afilado, y encima del casco lleva un bonete colorado.

(Romance del Cid Ruy Díaz, Cancionero de romances

(Anvers, 1550), f. 160, 223)

El tenso remanso que implica la descripción dentro del fluir de la narración sirve para comunicar enfáticamente al escucha o receptor del texto no sólo la osada valentía retadora del Cid, sino también la impresión que causaba. La descripción es una enumeración que pasa de la cabalgadura, a la vestimenta, a las armas para terminar con el tocado de los caballeros y el del Cid, éste descrito de manera un tanto extraña pues el "bonete colorado", posible elemento de ceremonia, establece un contraste al estar sobre el casco, cosa bastante improbable en la realidad, pero en la creatividad descriptiva establece un contraste que hasta podría tener el sentido de una burla del Cid. La descripción se apoya en un esquema característico del lenguaje romancístico tradicional que se puede sintetizar en la estructura formularia 'todos menos'.

Ejemplo de este frecuentísimo uso en la descripción lo tenemos de forma central en esta versión del sueño de doña Alda, la esposa de don Roldán:

En París está doña Alda, la esposa de don Roldán, trezientas damas con ella para la acompañar; todas visten un vestido, todas calçan un calçar, todas comen a una mesa, todas comían de un pan 
sino era doña Alda, que era la mayoral.

Las ciento hilavan oro, las ciento texen cendal, las ciento tañen instrumentos para doña Alda holgar.

$\mathrm{Al}$ son de los instrumentos doña Alda adormido se ha;

(Romance de doña Alda, Cancionero de romances

$$
\text { 1550, f. 102, 182) }
$$

En otros casos, la descripción llena la función de proporcionar indirectamente, a través de la caracterización del personaje, los antecedentes de la historia y por lo tanto su función es directamente complementaria de la narración. En el siguiente romance cidiano la descripción es la manera en que se expresa cómo van ocultándose los caballeros "buenos hombres" bajo la capa de labradores, aunque se explica que el ocultarse no es cobardía, elemento que podría corresponder a la fórmula de ir ocultándose "de día por las veredas, de noche por los caminos". La enumeración se complementa en los segundos hemistiquios con un elemento de contraste o explicación: aljubas-albornoces, capas-labradores, descansar de día-caminar de noche:

Por Guadalquivir arriba cabalgan caminadores, que, según dicen las gentes, ellos eran buenos hombres: ricas aljubas vestidas, y encima sus albornoces; capas traen aguaderas, a guisa de labradores. Daban cebada de día y caminaban de noche, no por miedo de los moros mas por las grandes calores. Por sus jornadas contadas llegados son a las Cortes: sálelos a recibir el rey con sus altos hombres. ${ }^{1}$

(De cómo el Cid acudió a las Cortes, Wolf y Hormann, Primavera y flor, 171)

Pero la descripción puede limitarse a un ámbito mucho más reducido y concretarse en el aspecto físico o externo de los personajes, con una función, a diferencia del ejemplo anterior, mucho más de ornato del texto y hasta cierto punto independiente de la propia narración.

También cuando la acción se quiere expresar con una visión panorámica se acude a formas de descripción. Así encontramos este recurso en el romance que cuenta la historia de la salida de Granada del alcaide Reduán acompañado del rey Boabdil:

1 Publicado en un pliego suelto del siglo XVI. Siguense ocho romances viejos, el primero De la presa de Tunez, etc.

Medievalia 48, 2016, pp. 71-82 
Reduán le respondía, sin demudarse la cara:

- Si lo dixe no me acuerdo, mas cumpliré mi palabra.Reduán pide mil hombres, el rey cinco mil le dava.

Por esa puerta de Elvira sale muy gran cavalgada.

¡Quánto del Moro hidalgo! ¡quánta de la yegua baya! ¡quánta de la lança en puño! ¡quánta del adarga blanca! ¡quánta de marlota verde! ¡quánta aljuba de escarlata! ¡quánta pluma y gentileza! ¡quánto capellar de grana! ¡quánto bayo borzeguí! ¡quánto laço qual esmalta! ¡quánta de la espuela de oro! ¡quánta estribera de plata! Toda es gente valerosa y experta para batalla: en medio de todos ellos el rey Chico de Granada. para recobrar Jaén, Pérez de Hita, Historia de los bandos, 198)

La descripción, a partir de la mención de los hidalgos moros, apela a una percepción sensorial a partir de una amplia gama colorística: bayo, blanco, verde, escarlata, grana, oro, plata. Se trata de caracterizar a gente capaz para la batalla, pero el recurso de la descripción apela al lujo y la vistosidad de la vestimenta, indudablemente el tono del romance cambia por la presencia de la descripción, el ámbito se vuelve más una evocación de tipo "morisco" que la noticia de una acción guerrera.

En este ámbito, la descripción también se puede emplear para subrayar una virtud específica o una característica particular del personaje, por ejemplo, la gallardía, el valor o la osadía de los dos caballeros zamoranos:

Riberas de Duero arriba cabalgan dos zamoranos: las armas llevan blancas, caballos rucios rodados, con sus espadas ceñidas, y sus puñales dorados, sus adargas a los pechos, y sus lanzas en las manos, ricas capas aguaderas por ir más disimulados, y por un repecho arriba arremeten los caballos que según dicen las gentes, padre e hijo son entrambos. ${ }^{2}$

(Reto de los dos caballeros zamoranos, Wolf y Hofmann, Primavera y flor, 143-144)

2 Publicado en un pliego suelto del siglo xvi. Riberas de Duero arriba caualgan dos zamoranos, con su glosa, hecha por Francisco de Argullo, etc. [Pliegos poéticos españoles en la Universidad de Praga, II, pl. 73, 257-262]. 
A pesar de la narratividad característica del género, también hay casos en que la descripción puede ser parte esencial de la narración y por lo tanto llegar a ser nuclear en la estructuración del romance, así lo encontramos en textos que podemos definir más estrictamente como "noticieros" o que tratan de alguna circunstancia particular. Tal es el caso del romance de la jura que exige el Cid al monarca castellano en Santa Gadea, donde el juramento, detallado y radical es el elemento nuclear del sentido del romance, por lo que la enumeración es la parte central de la historia que se cuenta:

En sancta Gadea de Burgos do juran los hijos dalgo, allí le toma la jura el Cid al rey castellano.

Las juras eran tan fuertes, que al buen rey ponen espanto;

sobre un cerrojo de hierro y una ballesta de palo:

-Villanos te maten, Alonso, villanos, que no hidalgos, de las Asturias de Oviedo, que no sean castellanos; mátente con aguijadas, no con lanças ni con dardos; con cuchillos cachicuernos, no con puñales dorados; abarcas traygan calçadas, que no çapatos con lazo; capas traygan aguaderas, no de contray, ni frisado; con camisones destopa, no de olanda, ni labrados; cavalleros vengan en burras, que no en mulas ni en cavallos; frenos traygan de cordel, que no cueros fogueados. Mátente por las aradas, que no en villas ni en poblado, sáquente el coraçón por el siniestro costado, si no dixeres la verdad de lo que te fuere preguntado: si fuyste, ni consentiste en la muerte de tu hermano.-

(Romance del juramento que tomó el Cid al rey don Alonso, Cancionero de romances, s.a., ff. 153-154)

Aquíla descripciónla constituye una enumeración de elementos antitéticos que constituyen el juramento: hierro-palo; asturianos-castellanos; aguijadas-dardos, cuchillo-puñales, cachicuernos-dorados; abarcas-zapatos. Incluso recurriendo a contrastes triádicos: capas aguaderas-contray y frisado; camisones de estopa-holanda y labrados; burras-mulas y caballos. En realidad, todo lo que sucede después con el destierro del Cid, tiene menos fuerza que el juramento, cuya fuerza radicaprecisamente enla acumulación de elementos enla descripción dela muerte quele espera al monarca en caso de haber consentido en la muerte de su hermano.

El mecanismo de la descripción es el mismo que se emplea cuando la noticia no es un acontecimiento sino una desgracia. En este tipo de romance 
las opciones son o acudir a la actualización dramática o apelar a la minuciosidad, en este último caso la descripción se funde entonces con la narración, en el cual cada acción se matiza y ornamenta con la descripción, como en este romance donde la descripción retrasa la herida a traición que provocará la muerte del Adelantado:

Álora, la bien cercada, tú que estás en par del río, cercóte el adelantado una mañana en domingo, de peones y hombres d'armas el campo bien guarnescido. Con la gran artillería hecho te avía un portillo. Viérades moros y moras todos huir al castillo: las moras llevavan ropa, los moros harina y trigo, y las moras de quinze años llevaban el oro fino y los moricos pequeños llevaban la passa e higo. Por cima de la muralla su pendón llevan tendido. Entre almena y almena quedado se avía un morico con una ballesta armada, y en ella puesto un cuadrillo. En altas vozes dezía, que la gente lo avía oído: - Treguas, treguas, adelantado, por tuyo se da el castillo_ ${ }^{3}$

(Muerte del adelantado en Álora, Pliegos de Praga, II, pl. 54, 105-109)

En este ejemplo también se ve otro uso que puede tener la descripción para crear la tensión dramática necesaria prolongando la secuencia inicial o previa.

Desde luego que el lenguaje y los tópicos que se emplean en estas descripciones son acordes con el estilo del romance valorado y aceptado por la colectividad, así los recursos que se usan en la descripción corresponden a un estilo que identificamos como tradicional, que se establece desde una estética colectiva. Uno, es el tono guerrero, de aliento épico o heroico, como en este romance del Cid donde la descripción del caballero precedida por la llamada formulística a verlo por donde viene actualizando dramáticamente la escena:

Helo, helo, por do viene el moro por la calçada, cavallero a la gineta encima una yegua baya,

3 Publicado en un pliego suelto del siglo Xvi. Nueva glosa fundada sobre aquel antiguo y verdadero romance de: Álora la bien cercada, etc. 
borzeguíes marroquíes y espuela de oro calçada, una adarga ante los pechos y en su mano una zagaya. Mirando estava a Valencia, como está tan bien cercada.

- $\mathrm{iOh}$ Valencia, oh Valencia, de mal fuego seas quemada! Primero fuyste de moros que de christianos ganada; si la lança no me miente a moros serás tornada.

(El moro que reta a Valencia, Cancionero de romances s. a., ff. 179r-180v)

Y otro es el tono de este romance que también usa la descripción y que es noticiero, pero que trata de crear un clima de lujo y frivolidad que contrastará con la noticia que se recibe de la pérdida de Antequera. La descripción parte de la ubicación tópica la mañana de san Juan y sigue con la descripción del ropaje de los caballeros en un juego cortés.

La mañana de Sant Joan al tiempo que alboreava, gran fiesta hazen los moros por la Vega de Granada, rebolviendo sus cavallos y jugando de las lanças, ricos pendones en ellas, broslados por sus amadas; ricas marlotas vestidas, texidas de oro y grana. El moro que amores tiene señales d'ello mostrava, y el que no tenía amores allí no escaramuçaba.

Las damas mozas los miran de las torres del Alhambra.

También se los mira el rey de dentro de la Alcaçaba.

Dando vozes vino un moro con la cara ensangrentada.

(Pérdida de Antequera y escaramuza de Alcalá, Silva de romances, f. 76,319 )

Más alejado todavía es el estilo que utiliza en la descripción del castillo de Fontefrida, una versión del romance — de tipo trovadoresco- de Rosaflorida. Aquí no se describen armas sino elementos extraordinarios, pero apelando siempre a los elementos formulísticos como es el brillo o resplandor mayor que el del "sol a mediodía":

En Castilla está un castillo, que se llama Rocha Frida:

al castillo llaman Rocha, y a la fonte llaman Frida.

El pie tenía de oro, y almenas de plata fina;

entre almena y almena está una piedra çafira:

tanto relumbra de noche como el sol a mediodía. 
Dentro estava una donzella que llaman Rosaflorida.

Siete condes la demandan, tres duques de Lombardía;

a todos les desdeñaba, tanta es su loçanía.

(Rosaflorida, Cancionero de romances s. a., f. 190)

La descripción puede involucrar al personaje, en este caso es lo que mira el rey Alfonso y la reflexión que le sugiere:

Mirava de Campo Viejo el rey de Aragón un día, mirava la mar d' España cómo menguaba y crescía; mirava naos y galeras, unas van y otras venían: unas venían de armada, otras de mercadería; unas van la vía de Flandes, otras la de Lombardía essas que vienen de guerra ¡oh cuán bien le parecían! Mirava la gran ciudad que Nápoles se dezía; mirava los tres castillos que la gran ciudad tenía: Castel Novo y Capuana, Santelmo, que reluzía, aqueste relumbra entr'ellos como el sol de mediodía. Lloraba de los sus ojos, de la su boca decía:

(Quejas de Alfonso V ante Nápoles, Silva de 1550, II, f. 78, 321)

En los romances de tema épico o noticiero la descriptividad permite la visión de conjunto y la caracterización de personajes, en los romances caballerescos o de temática absolutamente novelescos, también se limita el uso de la descriptividad y tiene funciones distintas. Completamente alejada de las anteriores es la descripción del romance de La bella en misa, cuya narratividad es mínima y la descripción de la bella es el núcleo del romance indudablemente amoroso y tendiente a lo lírico:

En Sevilla está una ermita cual dizen de San Simón adonde todas las damas ivan a hazer oración.

Allá va la mi señora, sobre todas la mejor: saya lleva sobre saya, mantillo de un tornasol, en la su boca muy linda lleva un poco de dulçor, en la su cara muy blanca lleva un poco de color y en los sus ojuelos garços lleva un poco de alcohol. A la entrada de la ermita, relumbrando como el sol, el abad que dize la misa no la puede dezir, non; 
monazillos que le ayudan no aciertan responder, non: por dezir "Amén, amén”, dezían "Amor, amor".

(La bella en misa, Pliegos poéticos de la Biblioteca Nacional, II, pl. XLIX) ${ }^{4}$

La descripción es entonces un recurso literario que en el romance tiene un uso limitado, pero desde luego no está ausente y sus funciones son recalcar la expresividad de una circunstancia o un personaje determinado apoyando los elementos narrativos. En la descripción claramente su construcción utiliza abundantemente los elementos formulísticos que caracterizan el lenguaje tradicional del Romancero.

El éxito de un romance en muchas ocasiones tiene que ver con el tema que trata y su relación con un momento histórico determinado, pero indudablemente la permanencia del texto en la memoria colectiva y la posibilidad de refuncionalización y difusión depende mucho del estilo empleado y en ese sentido domina la narración sobre la descripción, pero esta en ocasiones es el núcleo estético o poético del romance, son los "versos afortunados" que hacen que el texto perdure.

\section{BiBLIOGRAFÍA}

Cancionero de romances. Envers, Martin Nucio, s.a., ed. de Ramón Menéndez Pidal, Madrid: Consejo Superior de Investigaciones Científicas, 1945.

Cancionero de romances (Anvers, 1550), ed. de Antonio Rodríguez Moñino, Madrid: Castalia, 1967.

Di Stefano, Giuseppe, Romancero, Madrid: Taurus, 1993.

Díaz Roig, Mercedes, "La expresividad poética”, en Enrique Rodríguez Cepeda (ed.), Actas del Congreso Romancero-Cancionero, Madrid: Porrúa Turanzas, 1990, t. II, 333-342.

Pérez de Hita, Ginés, Historia de los bandos de los Zegríes y Abencerrajes. Guerras civiles de Granada, ed. de Paula Blanchard-Demouge, Madrid: El Museo Universal, 1983 [1 $1^{\text {a }}$ ed. Madrid, 1913-1915].

Pliegos poéticos de la Biblioteca Nacional, Madrid: Joyas Bibliográficas, 1957.

Pliegos poéticos españoles en la Universidad de Praga, 2 vols., ed. facsimilar, Madrid: Joyas Bibliográficas, 1960.

4 Publicada en un pliego suelto del siglo XVI. Romance nuevamente compuesto por Antonio Ruyz de Santillana: con su glosa. E otra glosa al romance que dice: En Sevilla esta una hermita, etc. 
Rodríguez Moñino, Antonio, La Silva de romances de Barcelona, 1561. Contribución al estudio bibliográfico del Romancero español del siglo XVI, Salamanca: Universidad de Salamanca, 1969.

Rodríguez Moñino, Antonio, Manual bibliográfico de cancioneros y romances impresos durante el siglo XVI, Madrid: Castalia, 1973.

Silva de romances (Zaragoza, 1550-1551), ed. de Antonio Rodríguez Moñino, Zaragoza: Cátedra Zaragoza, 1970.

Silva de varios romances (Barcelona, 1561), ed. de Antonio Rodríguez Moñino, Valencia: Castalia, 1953.

Timoneda, Joan, Rosas de romances (Valencia, 1573), ed. de Antonio Rodríguez Moñino y Daniel Devoto, Valencia: Castalia, 1963.

Wolf, Fernando José y Conrado Hofmann, Primavera y flor de romances o Colección de los más viejos y populares romances castellanos, en Marcelino Menéndez Pelayo, Antología de poetas líricos castellanos, t. VIII, Santander: Consejo Superior de Investigaciones Científicas, 1945 [1 $1^{\text {a }}$ ed. Asher, Berlin, 1856]. 